\title{
Alterações metabólicas em plantas de feijão originadas de sementes microbiolizadas por Pseudomonas sp. e inoculadas com Xanthomonas axonopodis pv. phaseoli
}

\author{
Eliane Gonçalves da Silva ${ }^{1}$, Andréa Bittencourt Moura ${ }^{2}$, Marcos Antonio Bacarin ${ }^{3}$, Carolina Cardoso Deuner ${ }^{4}$
}

\begin{abstract}
${ }^{1}$ Escola Superior de Agricultura Luiz de Queiroz (ESALQ/USP) - Departamento de Entomologia, Fitopatologia e Zoologia Agrícola, CEP: 13418-900, Piracicaba-SP. ${ }^{2}$ Universidade Federal de Pelotas - Departamento de Fitossanidade, Caixa Postal 354, CEP.: 96010-900, Pelotas-RS. ${ }^{3}$ Pesquisador CNPq Universidade Federal de Pelotas/IB - Departamento de Botânica. ${ }^{4}$ Universidade Federal de Lavras - Departamento de Fitopatologia, C.P. 37 CEP.: 37200-000, Lavras - MG. Parte do trabalho de dissertação do primeiro autor. Universidade Federal de Pelotas. (2004).

Autora para correspondência: Eliane Gonçalves da Silva.
\end{abstract}

Data de chegada: 09/03/2005. Aceito para publicação em: 20/03/2009

\section{RESUMO}

Silva E. G.; Moura A. B.; Bacarin, M.A.; Deuner, C. C. Alterações metabólicas em plantas de feijão originadas de sementes microbiolizadas por Pseudomonas sp. e inoculadas com Xanthomonas axonopodis pv. phaseoli. Summa Phytopathologica, v.35, n.2, p.98-104, 2009

Muitas enzimas estão envolvidas em reações de defesa de plantas contra patógenos. O objetivo deste trabalho foi verificar alterações na atividade de algumas destas enzimas em plantas de feijão originadas de sementes microbiolizadas com um isolado de Pseudomonas do grupo das fluorescentes (isolado DFs842). Sementes de feijão cultivar BRS Valente foram imersas em suspensão salina preparada a partir de crescimento bacteriano com $24 \mathrm{~h}$ do isolado de Pseudomonas $\left(\mathrm{OD}_{540}=0,5\right)$ sabidamente biocontroladora de Xanthomonas axonopodis pv. phaseoli. Como testemunhas, as sementes foram imersas em solução salina $(\mathrm{NaCl} 0,85 \%)$. Após a microbiolização por $5 \mathrm{~h} \mathrm{a} 10^{\circ} \mathrm{C}$, as sementes foram plantadas em vasos contendo uma mistura de solo não esterilizado, areia e esterco bovino (proporção 3:1:1), mantidos em casa de vegetação. A inoculação do patógeno foi realizada na terceira folha verdadeira de todas as plantas, fazendo-se cortes com tesoura imersa em suspensão salina do patógeno $(X$. axonopodis pv. phaseoli) preparada a partir de crescimento de $24 \mathrm{~h}$ $\left(\mathrm{OD}_{540}=0,4\right)$. Câmaras úmidas foram mantidas $24 \mathrm{~h}$ antes e após a inoculação. Para o preparo do extrato protéico, as três primeiras folhas verdadeiras foram coletadas individualmente em 5 épocas de coleta distintas: uma, momentos antes da inoculação e as demais nos tempos seis, 24,72 h e 15 dias após a inoculação. Este extrato protéico serviu de fonte para as determinações do teor de proteínas solúveis totais (PST), atividade da polifenol oxidase (PPO) e da peroxidase (PO), as quais foram realizadas por leituras espectrofotométricas. Os resultados demonstraram aumento significativo no teor de PST e na atividade de PPO nas plantas submetidas ao tratamento com isolado DFs842, sendo que, o teor de PST foi o dobro, em relação às plantas não tratadas. Também foi observado que, mesmo antes da inoculação do patógeno o teor de PST e a atividade de PPO nas plantas tratadas estavam bem maiores. Em relação à atividade de $\mathrm{PO}$ houve redução da mesma nas plantas tratadas com o isolado de Pseudomonas (DFs842). Esses resultados evidenciaram que a microbiolização das sementes provocou alterações metabólicas nas plantas delas originadas, pelo aumento do teor de PST e atividade de PPO, indicando uma provável participação destas enzimas na indução de resistência ativada pela microbiolização com o isolado de Pseudomonas (DFs842).

Palavras-chave adicionais: ISR, indução de resistência, rizobactérias, crestamento bacteriano comum e microbiolização de sementes.

\section{ABSTRACT}

Silva E. G.; Moura A. B.; Bacarin, M.A.; Deuner, C.C. Metabolic alterations on bean plants originated from microbiolization of seeds with Pseudomonas sp. and inoculated with Xanthomnas axonopodis pv. phaseoli. Summa Phytopathologica, v.35, n.2, p.98-104, 2009

Many enzymes are involved in plant defense against pathogens. The purpose of this study was to verify alterations in activity of some enzymes in bean plants originated from microbiolization of seeds with a fluorescent isolate (DFs842) of Pseudomonas. Bean seeds (cv. "BRS Valente") were immersed in a bacterial suspension of a 24 hours old Pseudomonas culture $\left(\mathrm{OD}_{540}=0,5\right)$ known as a Xanthomonas axonopodis pv. phaseoli biocontroler. Check treatment consisted of seeds immersed in a saline solution $(\mathrm{NaCl} 0,85 \%)$. After microbiolization for 5 hours at $10^{\circ} \mathrm{C}$, seeds were sowed in a non sterilized substrate composed of soil, sand and bovine manure mixture (3:1:1 ratio) disposed in pots in a greenhouse. The pathogen was inoculated by cutting the third true leaves with scissors previously immersed in the bacterial suspension $(X$. axonopodis pv. phaseoli) prepared from a 24 hours old culture $\left(\mathrm{OD}_{540}=0,4\right)$. Plants were kept in moister chambers for 24 hours before and after the inoculation. For protein extraction preparation, the three true leaves were collected individually at five different times: immediately before inoculation and 6, 24, 72 hours and 15 days after inoculation. The leaf extract was used for determination of total soluble proteins (TSP), and the activity of polyphenol oxidase (PPO) and peroxidase (PO) by spectrophometry. The results showed a significant increase in TSP content and PPO activity in plants treated with the isolated DFs842, when TSP content was the double of the non-treated plants. It was also observed that, even before pathogen inoculation, TSP content and PPO activity in plants treated was high. PO activity was reduced in Pseudomonas (DFs842) treated plants. The results showed evidence that metabolic alterations in plants are triggered upon seeds microbiolization, mainly due to the increase in TSP content and PPO activity. This indicates enzyme participation in induce host resistance with seed microbiolization with Pseudomonas (DFs842).

Keywords: ISR, induced resistance, rhizobacterias, bean common blight and seed microbiolization 
A indução de resistência de plantas a patógenos, também conhecida como ISR (Induced Systemic Resistance), é um fenômeno onde a resistência de plantas contra fitopatógenos é induzida de forma sistêmica pelo tratamento com microrganismos ou seus produtos ou utilizando compostos orgânicos ou inorgânicos (24).

Dentre os microrganismos usados para indução de resistência, as bactérias são as mais utilizadas, principalmente as chamadas de "Rizobactérias Promotoras de Crescimento de Plantas" (PGPR) (4, 9, 24).

Muitas enzimas estão envolvidas em reações de defesa contra fitopatógenos, incluindo as chamadas enzimas oxidativas, como as peroxidases (PO) e polifenol oxidase (PPO), que participam da formação de lignina e de outros compostos oxidativos, contribuindo para a formação de barreiras de defesa, reforçando a parede celular ou agindo diretamente sobre os patógenos $(2,10,21)$. Outras, como a tirosina amônia-liase (TAL) e fenilalanina amônia-liase (PAL), estão envolvidas com a produção de fitoalexinas e de compostos fenólicos (20).

A capacidade de agentes em controlar diversas doenças de origens distintas, indica que mais de um mecanismo de proteção da planta podem estar envolvidos $(16,22,24)$. Esta característica é observada na indução de resistência sistêmica, na qual, a quantificação de enzimas específicas, pode indicar o estado de indução na interação plantapatógeno.

O crestamento bacteriano, causado por Xanthomonas axonopodis pv. phaseoli, é considerada uma das principais causas de perdas na cultura do feijão (Phaseolus vulgaris L.). Seu controle é realizado por medidas preventivas, como uso de sementes sadias, emprego de cultivares resistentes, rotação de culturas, pois o controle químico geralmente é ineficiente e economicamente inviável. Por outro lado, resultados, ainda que iniciais, mostram grande potencial do uso de bactérias como biocontroladoras, destacando-se o isolado DFs842, obtido de filoplano de plantas de feijão e selecionado para o biocontrole do crestamento bacteriano por Zanatta et al. (25) e Silva et al. (17). Neste sentido, o objetivo deste trabalho foi verificar se o mecanismo de proteção de plantas de feijão, originadas de sementes microbiolizadas com isolado de Pseudomonas (DFs842), pode ser explicado pela alteração na atividade das enzimas peroxidase e polifenol oxidase.

\section{MATERIAL E MÉTODOS}

Sementes de feijão cultivar BRS Valente foram imersas em suspensão bacteriana do isolado de Pseudomonas sp. (DFs842), cultivado por $24 \mathrm{~h}$ em meio 523 (7), preparada com solução salina esterilizada $(0,85 \% \mathrm{NaCl})$, cuja concentração foi ajustada em espectrofotômetro para $\mathrm{OD}_{540}=0,5$. Para tratamento controle, utilizaram-se sementes imersas somente em solução salina. As sementes foram postas para agitar durante 5 horas à $10^{\circ} \mathrm{C}$ e plantadas em vasos com capacidade 2 litros, contendo mistura de solo, areia e esterco bovino, na proporção 3:1:1. Os vasos foram mantidos em casa de vegetação e aos 10 dias após a emergência foi feita aplicação de solução nutritiva em todos os tratamentos. O ensaio foi conduzido de forma inteiramente casualizada, em casa de vegetação, em 40 vasos, contendo duas plantas cada, sendo que estes corresponderam à dois tratamentos, cinco épocas de coleta em 4 repetições.

\section{Preparo do inóculo e inoculação}

$\mathrm{O}$ inóculo constituiu-se de suspensão de X. axonopodis pv. phaseoli preparada a partir de cultura com 48 horas de crescimento em meio 523 de Kado \& Heskett (7), incubada a $28^{\circ} \mathrm{C}$ com concentração determinada em espectrofotômetro para $\mathrm{OD}_{540}=0,4$.

A inoculação de todas as plantas, inclusive da testemunha, foi realizada na terceira folha verdadeira, quando a mesma encontrava-se plenamente desenvolvida em todas as plantas. Utilizou-se o método de incisão realizado com tesoura imersa em suspensão do patógeno, fazendo-se um corte em cada lado dos folíolos, num total de seis cortes por planta, como descrito por Rava (14). Câmaras úmidas foram mantidas $24 \mathrm{~h}$ antes e após a inoculação.

\section{Coleta de material vegetal}

Foram realizadas cinco coletas de material vegetal para a avaliação da atividade enzimática, a primeira, momentos antes da inoculação do patógeno e as demais coletas nos tempos seis, 24, 72 horas e 15 dias após a inoculação do patógeno. As três primeiras folhas verdadeiras, surgidas após as folhas cotiledonares $(\mathrm{F} 1=$ primeira folha trifoliolada; F2=segunda folha trifoliolada; F3= terceira folha trifoliolada) de cada tratamento foram coletadas, individualmente, acondicionadas em sacos plásticos bem fechados e imediatamente armazenadas em freezer até o momento do preparo do extrato para quantificação das enzimas.

\section{Preparo das amostras para atividade enzimática}

No preparo do extrato, foram retirados aproximadamente $0,25 \mathrm{~g}$ de tecido foliar de cada amostra, trituradas em almofariz com pistilo, adicionando-se ao macerado $2 \mathrm{~mL}$ de solução tampão fosfato de sódio 0,1 M, pH 7,0 (tampão de extração), mais polivinilpirrolidona 1\% (p/ v). O homogenato resultante de cada amostra foi coletado e centrifugado a $25.000 \mathrm{~g}$ por 15 minutos a $4^{\circ} \mathrm{C}$. O sobrenadante obtido foi coletado, ajustando-se para um volume de $10 \mathrm{~mL}$ com tampão de extração e armazenando-se em freezer para posterior determinação de proteínas totais e das atividades de peroxidase e polifenol oxidase.

\section{Determinação de proteínas totais}

A determinação do teor de proteínas solúveis totais foi realizada por leitura espectrofotométrica direta, na faixa de UV, utilizando-se comprimento de onda de 280 e $260 \mathrm{~nm}$ (15).

\section{Determinação da atividade de peroxidase}

A atividade de peroxidase (PO) foi determinada a $25^{\circ} \mathrm{C}$ pela medida da taxa de incremento inicial na absorbância a $470 \mathrm{~nm}$. O meio da reação continha $0,3 \mathrm{~mL}$ de extrato protéico, $2,7 \mathrm{~mL}$ de guaiacol $0,05 \%$ e $0,1 \mathrm{~mL}$ de peróxido de hidrogênio $0,2 \%$ em tampão fosfato $0,1 \mathrm{M}$, em pH 6,5 (1).

A atividade enzimática foi calculada pela medida da declividade da linha de reação ao tempo zero (taxa inicial). A unidade de atividade enzimática foi definida como a mudança na absorbância por segundo por miligrama de proteínas solúveis totais (atividade específica) ou pela mudança na absorbância por grama de matéria fresca (atividade total).

\section{Determinação da atividade de polifenol oxidase}

A atividade de polifenol oxidase (PPO) foi determinada a $25^{\circ} \mathrm{C}$ pela medida da taxa de incremento inicial na absorbância a $420 \mathrm{~nm}$. Utilizou-se para a reação meio contendo $0,3 \mathrm{~mL}$ de extrato protéico, $2,7 \mathrm{~mL}$ de pirocatecol $20 \mathrm{mM}$ preparado em tampão fosfato $0,1 \mathrm{M}$, $\mathrm{pH} 6,5$ (11).

A atividade enzimática foi calculada pela medida da declividade da linha de reação ao tempo zero (taxa inicial). A unidade de atividade enzimática foi definida como a mudança na absorbância por segundo por miligrama de proteínas solúvel total (atividade específica) ou pela mudança na absorbância por grama de matéria fresca (atividade total). 


\section{Análises Estatísticas}

Os dados obtidos de todas as determinações foram submetidos à análise de variância e as médias comparadas por LSMEAN a 1\%.

\section{RESULTADOS E DISCUSSÃO}

A microbiolização das sementes proporcionou um aumento significativo da concentração de proteínas solúveis totais $(87,5 \%)$, da atividade total de polifenol oxidase $(48 \%)$ e reduziu a atividade específica de polifenol oxidase e da atividade específica de peroxidase em relação às plantas originadas de sementes não microbiolizadas (testemunhas). Para atividade total peroxidase não houve efeito de tratamento.

Em relação às épocas de coleta, houve aumento significativo da concentração de proteínas solúveis totais após a inoculação do patógeno (0h) sendo que, a maior concentração ocorreu após 6h (48\%), apresentando redução progressiva, porém, não significativa até $72 \mathrm{~h}$. Após 15 dias, a concentração estava similar ao tempo $0 \mathrm{~h}$. A atividade total de peroxidase não sofreu influência do tratamento, porém quando se observa a atividade específica de peroxidase, nota-se que os maiores valores ocorreram antes da inoculação da bactéria patogênica e após 72 horas e 15 dias da inoculação, não ocorrendo diferenças entre estas três épocas de avaliação, porém, houve redução significativa (até 34\% após 24 h) da atividade da referida enzima nas épocas intermediárias.

A maior atividade total de polifenol oxidase, que diferiu dos valores das demais épocas de avaliação, ocorreu após $72 \mathrm{~h}$ (25\%), embora após $6 \mathrm{~h}$ e $24 \mathrm{~h}$ da inoculação tenha ocorrido redução (até $29 \%$ ). Aos 15 dias, pôde se notar atividade similar ao do momento da inoculação. A maior atividade específica de polifenol oxidase também ocorreu após $72 \mathrm{~h}$ da inoculação (17\%) seguida das avaliações aos 15 dias e no momento da inoculação ( $0 \mathrm{~h}$ ), das quais não diferiu, embora, inicialmente, tenha ocorrido redução significativa (até $35 \%$ após 6 h).

Quando se observou o efeito do tipo de folha, verificou-se que este apresentou significância para proteínas solúveis totais e para atividade total e específica de polifenol oxidase. A folha inoculada e a imediatamente anterior a ela (F3 e F2, respectivamente) apresentaram concentrações de proteínas solúveis totais superiores à primeira $(\mathrm{F} 1)$. A atividade de polifenol oxidase foi decrescente da primeira para a última folha avaliada, sendo que, para a atividade total, as três folhas foram diferentes entre si e para a específica, a primeira (F1) foi diferente das demais.

A interação época e folha não foi significativa para nenhum dos parâmetros avaliados e a interação folha e tempo foi significativa somente para proteínas solúveis totais. A maior concentração de proteínas solúveis totais foi observada na terceira folha no momento da inoculação ( $0 \mathrm{~h})$, sendo significativamente maior que as demais folhas. Após 6h, a concentração na folha inoculada foi reduzida a $70 \%$ do valor inicial, diferindo da folha 2, cujo teor foi a maior. Após 24 horas, a concentração tornou a aumentar, mostrando para a folha inoculada, valor superior a do momento antes da inoculação (0h) e também às demais, porém, sem, no entanto, diferir estatisticamente destas. Setenta e duas horas após a inoculação, a folha inoculada e a imediatamente anterior a ela (F2) foram superiores à primeira folha. Ao final da

Tabela 1 - Teor de proteínas solúveis totais (PST), atividade total (POT) e específica (POE) de peroxidase, total (PPOT) e específica (PPOE) de polifenol oxidase, em amostras de folhas de feijão oriundas de sementes microbiolizadas com o isolado DFs842 e de sementes não tratadas

\begin{tabular}{lcccccc}
\hline Tratamentos & $\begin{array}{c}\mathrm{PST}^{* *} \\
\left(\mathrm{mg} \cdot \mathrm{g}^{-1} \mathrm{MF}\right)\end{array}$ & $\begin{array}{c}\mathrm{POT}^{\mathrm{NS}} \\
\left(\Delta \mathrm{Aseg}^{-1} \mathrm{~g}^{-1} \mathrm{MF}\right)\end{array}$ & $\begin{array}{c}\text { POE }^{* *} \\
\left(\Delta \mathrm{A} \mathrm{seg}^{-1} \mathrm{mg}^{-1} \mathrm{PST}\right)\end{array}$ & $\begin{array}{c}\mathrm{PPOT}^{* *} \\
\left(\Delta \mathrm{A} \mathrm{seg}^{-1} \mathrm{~g}^{-1} \mathrm{MF}\right)\end{array}$ & $\begin{array}{c}\mathrm{PPOE}^{*} \\
\left(\Delta \mathrm{A} \mathrm{seg} \mathrm{mg}^{-1} \mathrm{PST}\right)\end{array}$ \\
\hline DFs842 & $14,74 \mathrm{~A}$ & $0,221 \mathrm{~A}$ & $0,019 \mathrm{~B}$ & $0,218 \mathrm{~A}$ & $0,020 \mathrm{~B}$ \\
Testemunha & $7,86 \mathrm{~B}$ & $0,238 \mathrm{~A}$ & $0,040 \mathrm{~A}$ & $0,147 \mathrm{~B}$ & $0,026 \mathrm{~A}$ \\
\hline
\end{tabular}

Médias seguidas por letras distintas na coluna diferem entre si pelo teste de LSMEAN, ** significativo a $1 \%$, * significativo a $5 \%$ e ${ }^{\text {NS }}$ não significativo.

Tabela 2 - Teor de proteínas solúveis totais (PST), atividade total (POT) e específica (POE) de peroxidase, total (PPOT) e específica (PPOE) de polifenol oxidase, em função do tempo após a inoculação das folhas de feijão

\begin{tabular}{|c|c|c|c|c|c|}
\hline Tempo & $\begin{array}{c}\mathrm{PST}^{* *} \\
\left(\mathrm{mg} \cdot \mathrm{g}^{-1} \mathrm{MF}\right)\end{array}$ & $\begin{array}{c}\text { POT }^{\mathrm{NS}} \\
\left(\Delta \text { Aseg }^{-1} \mathrm{~g}^{-1} \mathrm{MF}\right)\end{array}$ & $\begin{array}{c}\mathrm{POE}^{* *} \\
\left(\Delta \mathrm{A} \mathrm{seg}^{-1} \mathrm{mg}^{-1} \mathrm{PST}\right)\end{array}$ & $\begin{array}{c}\text { PPOT }^{* *} \\
\left(\Delta \mathrm{A} \mathrm{seg}^{-1} \mathrm{~g}^{-1} \mathrm{MF}\right)\end{array}$ & $\begin{array}{c}\mathrm{PPOE}^{*} \\
\left(\Delta \mathrm{A} \mathrm{seg}^{-1} \mathrm{mg}^{-1} \mathrm{PST}\right)\end{array}$ \\
\hline $0 \mathrm{~h}$ & $9,23 \mathrm{BC}$ & $0,234 \mathrm{~A}$ & $0,040 \mathrm{~A}$ & $0,190 \mathrm{~B}$ & $0,025 \mathrm{ABC}$ \\
\hline $6 \mathrm{~h}$ & $13,72 \mathrm{~A}$ & $0,207 \mathrm{~A}$ & $0,024 \mathrm{BC}$ & $0,173 \mathrm{BC}$ & $0,016 \mathrm{C}$ \\
\hline $24 \mathrm{~h}$ & $12,84 \mathrm{~A}$ & $0,229 \mathrm{~A}$ & $0,022 \mathrm{C}$ & $0,136 \mathrm{C}$ & $0,018 \mathrm{BC}$ \\
\hline $72 \mathrm{~h}$ & $11,56 \mathrm{AB}$ & $0,236 \mathrm{~A}$ & $0,029 \mathrm{BC}$ & $0,238 \mathrm{~A}$ & $0,029 \mathrm{~A}$ \\
\hline 15 dias & $9,14 \mathrm{C}$ & $0,242 \mathrm{~A}$ & $0,033 \mathrm{AB}$ & $0,166 \mathrm{BC}$ & $0,026 \mathrm{AB}$ \\
\hline
\end{tabular}

Médias seguidas por letras distintas na coluna diferem entre si pelo teste de LSMEAN, ${ }^{* *}$ significativo a $1 \%$, ${ }^{*}$ significativo a $5 \%$ e ${ }^{\text {NS }}$ não significativo.

Tabela 3 - Teor de proteínas solúveis totais (PST), atividade total (POT) e específica (POE) de peroxidase, total (PPOT) e específica (PPOE) de polifenol oxidase, observadas nas 3 folhas de feijão avaliadas

\begin{tabular}{lccccc}
\hline Folha & $\begin{array}{c}\text { PST }^{* *} \\
\left(\mathrm{mg} \cdot \mathrm{g}^{-1} \mathrm{MF}\right)\end{array}$ & $\begin{array}{c}\text { POT NS }^{\mathrm{NS}} \\
\left(\Delta \mathrm{Aseg}^{-1} \mathrm{~g}^{-1} \mathrm{MF}\right)\end{array}$ & $\begin{array}{c}\text { POE }^{* *} \\
\left(\Delta \mathrm{Ase}^{-1} \mathrm{mg}^{-1} \mathrm{PST}\right)\end{array}$ & $\begin{array}{c}\mathrm{PPOT}^{* *} \\
\left(\Delta \mathrm{Aseg}^{-1} \mathrm{~g}^{-1} \mathrm{MF}\right)\end{array}$ & $\begin{array}{c}\mathrm{PPOE}^{* *} \\
\left(\Delta \mathrm{A} \mathrm{seg} \mathrm{mg}^{-1} \mathrm{PST}\right)\end{array}$ \\
\hline F1 & $9,62 \mathrm{~B}$ & $0,231 \mathrm{~A}$ & $0,031 \mathrm{~A}$ & $0,228 \mathrm{~A}$ & $0,030 \mathrm{~A}$ \\
F2 & $12,46 \mathrm{~A}$ & $0,228 \mathrm{~A}$ & $0,028 \mathrm{~A}$ & $0,174 \mathrm{~B}$ & $0,022 \mathrm{~B}$ \\
F3 & $11,82 \mathrm{~A}$ & $0,230 \mathrm{~A}$ & $0,030 \mathrm{~A}$ & $0,138 \mathrm{C}$ & $0,016 \mathrm{~B}$ \\
\hline
\end{tabular}

Médias seguidas por letras distintas coluna diferem entre si pelo teste de LSMEAN, ${ }^{* *}$ significativo a $1 \%$, ${ }^{*}$ significativo a $5 \%$ e ${ }^{\text {NS }}$ não significativo. 
Tabela 4 - Concentração de proteínas solúveis totais $\left(\mathrm{mg}^{-1} \mathrm{MF}\right)$ determinadas em amostra de plantas de feijão nas três folhas de feijão avaliadas, em função do tempo após a inoculação

\begin{tabular}{llccc}
\hline & \multicolumn{4}{c}{ Épocas de coleta } \\
\cline { 2 - 5 } Folha & $0 \mathrm{~h}$ & $6 \mathrm{~h}$ & $24 \mathrm{~h}$ & $72 \mathrm{~h}$ \\
\hline F1 & $7,58 \mathrm{~B}$ & $12,24 \mathrm{~B}$ & $10,54 \mathrm{~A}$ & $9,00 \mathrm{~B}$ \\
F2 & $6,16 \mathrm{~B}$ & $19,16 \mathrm{~A}$ & $13,70 \mathrm{~A}$ & $13,94 \mathrm{~A}$ \\
F3 & $13,96 \mathrm{~A}$ & $9,76 \mathrm{~B}$ & $14,27 \mathrm{~A}$ & $11,75 \mathrm{~A}$ \\
\hline
\end{tabular}

Médias seguidas por letras distintas na coluna diferem entre si pelo teste de LSMEAN a $1 \%$.

avaliação (15 dias), a folha inoculada permanecia com a maior concentração, sem, porém, apresentar diferença estatística em relação às demais.

Pôde-se verificar a ocorrência de interação entre tratamento e tempo para concentração de proteínas solúveis totais, atividade específica de peroxidase, atividade total e específica de polifenol oxidase.

$\mathrm{O}$ aumento da concentração de proteínas solúveis totais proporcionado pelo isolado bacteriano DFs842 foi observado também nas diferentes épocas de coleta de material, desde o momento da inoculação, com exceção às $24 \mathrm{~h}$ após a inoculação. Foi possível observar, nas plantas oriundas de sementes microbiolizadas com o isolado DFs842, que houve intenso aumento na concentração e que o maior valor ocorreu nas primeiras $6 \mathrm{~h}(53 \%)$, apresentando diferenças

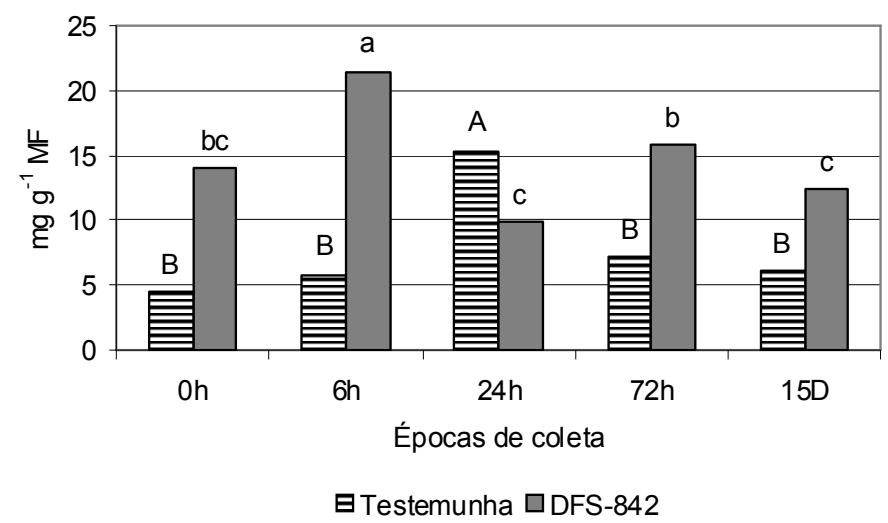

Figura 1. Concentração de proteínas solúveis totais em plantas tratadas com isolado DFs842 e plantas testemunhas, avaliadas em 5 épocas distintas. As letras maiúsculas representam as médias para testemunha e as minúsculas, para o tratamento, médias com letras distintas diferem entre si pelo teste de LSMEAN a $1 \%$.

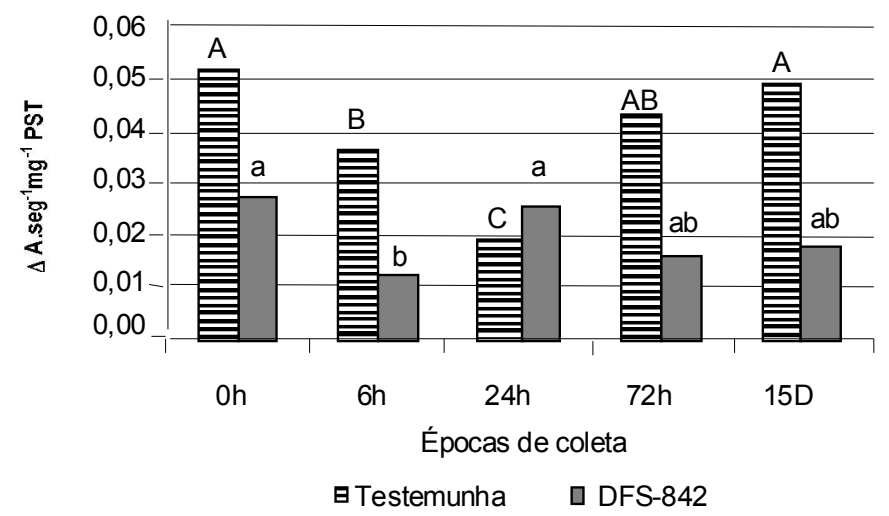

Figura 2. Atividade específica de peroxidase em plantas tratadas com isolado DFs842 e plantas testemunhas, avaliadas em 5 épocas. As letras maiúsculas representam as médias para testemunha e as minúsculas, para o tratamento, médias com letras distintas diferem entre si pelo teste de LSMEAN a $1 \%$.

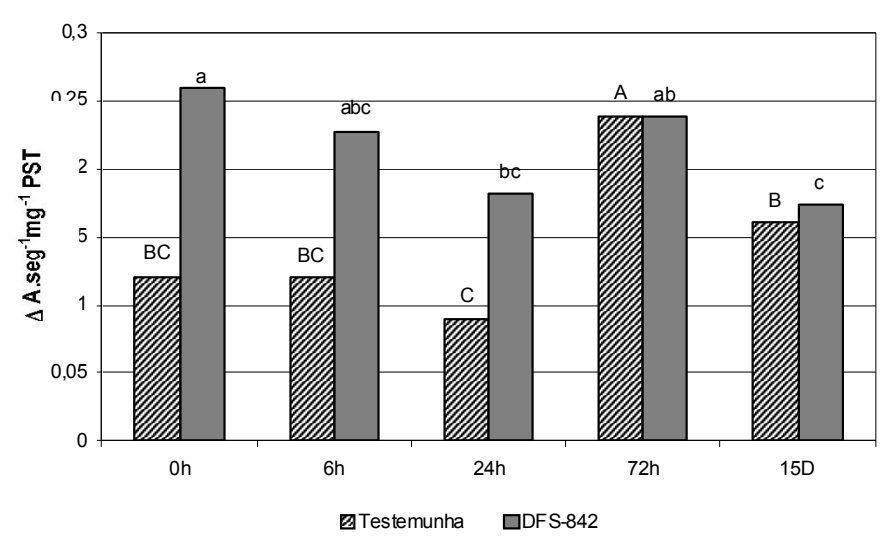

Figura 3 - Atividade total de polifenol oxidase em plantas submetidas ao tratamento DFs842 e plantas testemunhas, avaliadas em 5 épocas. As letras maiúsculas representam as médias para testemunha e as minúsculas, para o tratamento, médias com letras distintas diferem entre si pelo teste de LSMEAN a $1 \%$.

estatísticas em relação às demais épocas de avaliação. Por outro lado, nas plantas testemunhas, este aumento ocorreu somente após $24 \mathrm{~h}$.

A atividade específica de peroxidase, nas plantas cujas sementes foram tratadas com o isolado DFs842, inicialmente foi reduzida significativamente, porém após $24 \mathrm{~h}$ já havia restabelecido ao patamar inicial, não diferenciando do nível inicial e mantendo-se estatisticamente igual a este até 15 dias após a inoculação. Nas plantas não tratadas também houve um decréscimo de atividade intenso e significativo durante as primeiras 24 horas, que foi minimizado após $72 \mathrm{~h}$.

A atividade total de polifenol oxidase nas plantas originadas de sementes tratadas com o isolado DFs 842 apresentou redução seis e 24 horas depois, recuperando após 72 horas, embora tenha reduzido novamente aos 15 dias. Nas plantas testemunhas, a atividade foi crescente até 72 horas sendo superior às demais épocas de avaliação, porém este ainda permaneceu inferior ao nível inicial das plantas tratadas.

Nas plantas originadas de sementes microbiolizadas com o isolado DFs842, a maior atividade de específica de polifenol oxidase ocorreu no momento da inoculação, reduzindo significativamente após $6 \mathrm{~h}$ da inoculação e elevando-se ao nível inicial nas demais épocas, sem que ocorresse diferença significativa. Para a testemunha, as maiores atividades ocorreram após 72 horas e 15 dias da inoculação, nas outras épocas de avaliação, a atividade foi significativamente inferior.

Interação tripla significativa ocorreu somente para concentração de proteínas solúveis totais e para atividade específica de peroxidase. Em plantas sob efeito do isolado de Pseudomonas, observou-se que no tempo zero a concentração de proteínas solúveis totais nas folhas inoculadas (F3) era significativamente superior, chegando a mais que o dobro das demais. Seis horas após, a segunda folha apresentava concentração aumentada, sendo maior que nas outras folhas avaliadas, pois em F3 a concentração havia reduzido e em F1, aumentado. Nas 


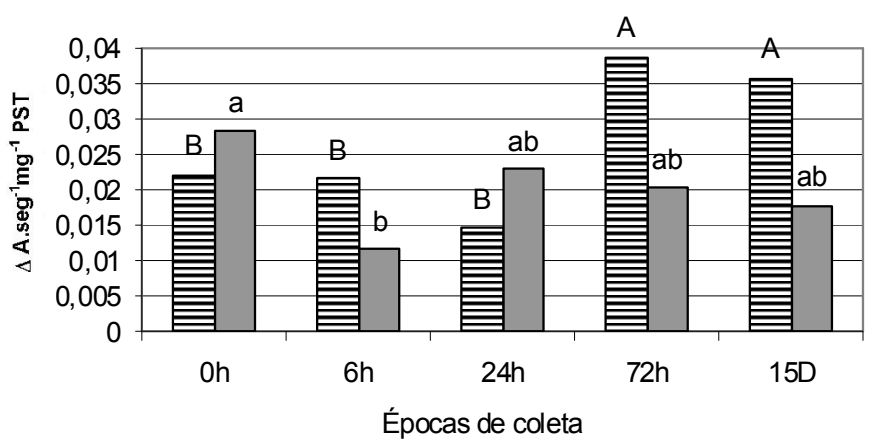

目Testemunha $\square$ DFS-842

Figura 4 - Atividade específica de polifenol oxidase em amostras de plantas submetidas ao tratamento DFs842 e plantas testemunhas, observadas nas diferentes épocas. As letras maiúsculas representam as médias para testemunha e as minúsculas, para o tratamento, médias com letras distintas diferem entre si pelo teste de LSMEAN a $1 \%$.

horas seguintes, houve redução da concentração em todas as folhas, sendo que em F1 apresentou maior valor, embora este não diferisse de F3 e nem esta de F2. Nas horas posteriores, houve diminuição da concentração em F1 e aumento em F2 e F3, mostrando diferenças significativas. Ao final de 15 dias, não foi possível verificar quaisquer
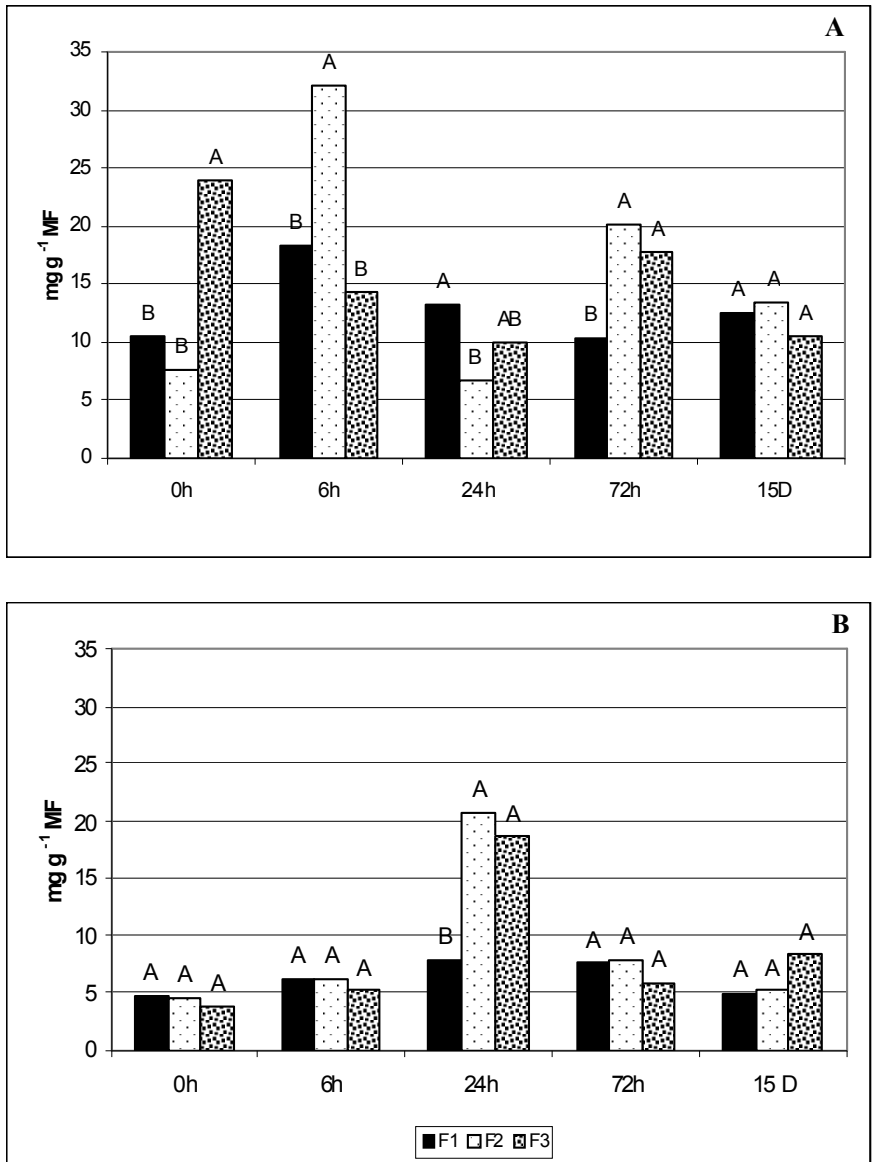

Figura 05 - Concentração de proteínas solúveis totais em plantas submetidas ao tratamento DFs842 (A) e plantas testemunhas (B), observadas nas diferentes épocas nas três folhas avaliadas. Letras distintas representam diferenças significativas entre as folhas avaliadas dentre as épocas de coleta, pelo teste LSMEAN a $1 \%$. diferenças entre as folhas avaliadas. Nas plantas testemunha, só houve diferença após 24 horas, que foi a época de coleta que apresentou maiores concentrações para as três folhas.

Nas plantas originadas de sementes microbiolizadas com o isolado DFs842, no tempo zero, as duas primeiras folhas apresentavam atividade específica de peroxidase superior à folha inoculada. Passadas 6 horas, a atividade foi reduzida em todas as folhas, sem que diferenças pudessem ser detectadas. Vinte quatro horas após a inoculação, a atividade havia aumentado, em F2 não diferindo F1. Na avaliação às 72 horas, a atividade de F1 aumentou e de F2 e F3 reduziram, sem, no entanto, apresentarem diferenças estatísticas, o que também ocorreu após 15 dias, embora o nível de F3 tenha novamente aumentado e de F1 e F2, diminuído.

Nas plantas não tratadas, a folha inoculada apresentou atividade específica de peroxidase superior a F1 e F2, que foram reduzidos após 6 e também 24 horas. Nestas avaliações não foi possível observar diferenças entre as diferentes folhas. Após 72 horas, verificou-se aumento da atividade peroxidase em todas as folhas, destacando-se F3, que diferiu das demais. Este aumento pôde ser observado após 15 dias nas folhas F2 e F1, que diferiram de F3 em que se observou redução da atividade.

De modo geral, pode-se dizer que a microbiolização das sementes produziu alterações nas atividades metabólicas das plantas delas originadas, aumentando significativamente os parâmetros avaliados, destacando-se a concentração de proteínas solúveis totais. Estes resultados estão em concordância com o fato do aumento das PRPs (proteínas relacionadas à patogênese) estar ativamente relacionado ao fenômeno de resistência induzida (22).

Pôde ser observado, que estas alterações já podiam ser detectadas
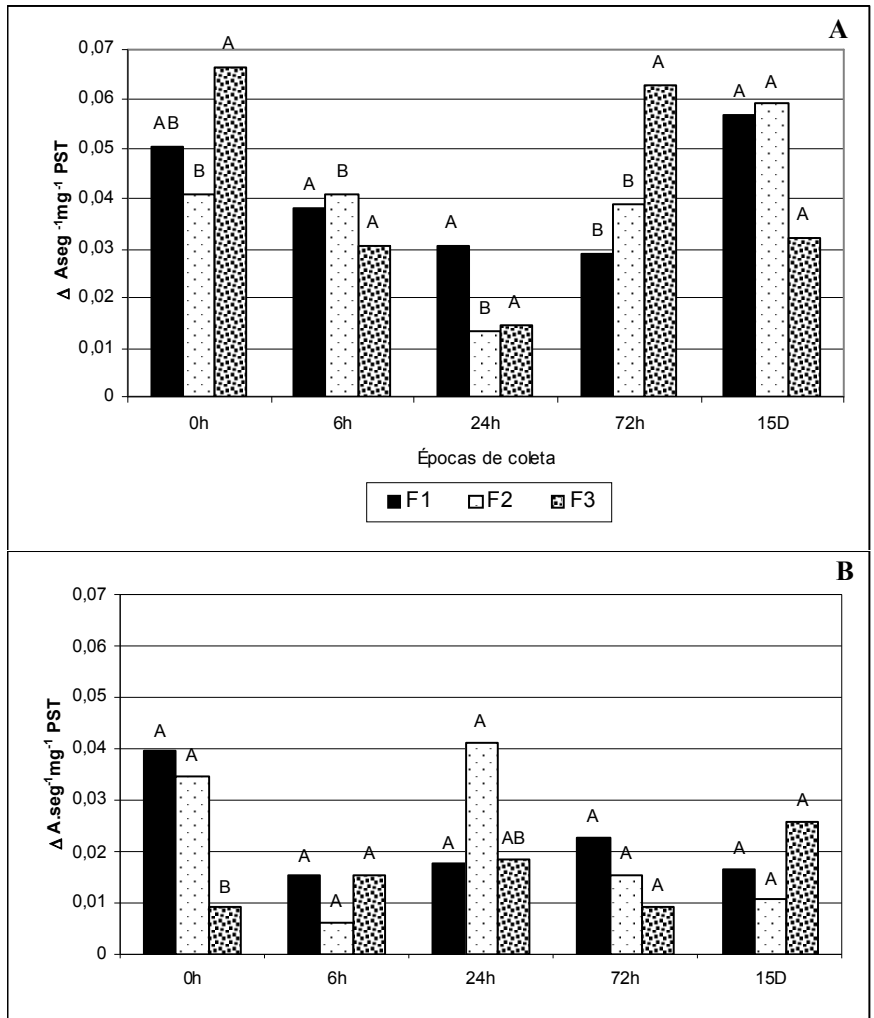

Figura 06 - Atividade específica de peroxidase determinada em plantas submetidas ao tratamento DFs842 (A) e plantas testemunha (B), observadas nas diferentes épocas nas três folhas avaliadas. Letras distintas representam diferenças significativas entre as folhas avaliadas dentre as épocas de coleta, pelo teste LSMEAN a $1 \%$. 
mesmo antes da inoculação (0 hora), posto que, não sendo a indução imediata (24), parece ter havido um acúmulo até o momento da inoculação, uma vez que o indutor (isolado de Pseudomonas DFs842) foi aplicado à semente, estando presente desde o início da germinação, e que esta diferença era significativamente expressiva na folha inoculada. Embora exista um número expressivo de pesquisas verificando alterações metabólicas provocadas por bactérias biocontroladoras, poucas avaliaram as alterações antes da inoculação do patógeno. Ramammorthy e colaboradores (13), microbiolizando sementes de tomate, seguida por infestação adicional do solo com Pseudomonas fluorescens Pf1, para controle de Fusarium oxysporum f. sp. lycopersici, verificaram que níveis de compostos fenólicos, atividade de fenilalanina amônia-liase, peroxidase, polifenol oxidase, glucanase e quitinase, assim como os dados aqui obtidos para proteínas solúveis totais e polifenoloxidase, encontravam-se superiores às plantas da testemunha.

Também ficou evidente que nas plantas protegidas, a resposta à inoculação foi mais rápida, isto é, houve aumento da concentração de proteínas solúveis totais nas primeiras seis horas e também uma recuperação dos níveis de atividades total e específica de polifenol oxidase mais rápida do que nas plantas testemunha, assim como observado em alguns trabalhos $(12,13)$.

Parece não ter havido participação de peroxidase no biocontrole do patógeno em questão, o que pode ser explicado pelo fato de geralmente sua atividade estar associada com estágios mais tardios do processo de infecção, e estar ligada a processos de lignificação, embora possa também gerar peróxido de hidrogênio, que inibe o patógeno diretamente ou gera outros radicais livres que têm efeito antimicrobiano (6).

Resultados relacionando biocontrole à indução de resistência pelo aumento de proteínas, principalmente pelo aumento de atividade algumas enzimas são encontrados com relativa freqüência na literatura. Alguns destes trabalhos buscam o controle de bactérias fitopatogênicas como de Pseudomonas syringae pv. tomato pela microbiolização de sementes de tomate com rizobactéria mostrando aumento de atividade de peroxidases (23), ou com antagonista UFV-IEA6, também provocando aumento de peroxidase (18), embora em ambos os trabalhos tenham sido avaliadas as atividades também de outras enzimas (felilalanina amônia-liases, glucanases, lipoxigenases, peroxidases e polifenoloxidase); outros, de viroses como a causada por $T o M V$, quando verificou-se que além do aumento da atividade de enzimas, o biocontrole ocorria também pelo aumento de teores de proteínas como o provocado pela aplicação de ácido salićlico e de ácido acetil salićlico, com comportamento diferenciado em dois cultivares de tomate inoculados (8).

O biocontrole pode ser atribuído a alterações da atividade de polifenol oxidase e de outros compostos. Soares et al. (19) observaram aumento da atividade de peroxidase, polifenol oxidase e níveis de proteínas solúveis totais em plantas de feijão pulverizadas com o indutor de resistência acibenzolar-S-metil (ASM), em plantas coletadas aos $5,10,15$ e 20 dias após a aplicação do indutor, sendo que a atividade de peroxidase foi maior nas folhas e nos caules e para as demais variáveis somente nos caules. Trabalhos buscando o controle de outras doenças do feijão também mostraram a participação de diversas enzimas. Campos et al. (5) atribuíram maior resistência de alguns cultivares desafiados por Colletotrichum lindemuthianum (isolado 33/95) ao aumento nas atividades de peroxidase e polifenol oxidase, principalmente quando as plantas eram previamente tratadas com ácido salicílico e com $C$. lindemuthianum raça delta, considerados como indutores. Para o controle de Macrophomina phaseolina, nitrato de cobalto aplicado em imersão de sementes ou molhamento do solo provocou aumento de atividade de peroxidase e polifenol oxidase, reduzindo a incidência da podridão cinzenta (3).

Embora os resultados obtidos neste trabalho indiquem que a microbiolização das sementes de feijão com o isolado de Pseudomonas DFs 842 foi responsável por indução de resistência atribuída ao aumento expressivo de concentração de proteínas solúveis totais e da atividade de polifenol oxidase, não se descarta a hipótese da participação de outras enzimas que se encontram na fração protéica solúvel.

\section{REFERÊNCIAS BIBLIOGRÁFICAS}

1.Aeby, H. Catalase in vitro. Methods Enzymology, v. 105, p. $121-126,1984$.

2.Avdiushko, S. A.; Ye, X. S.; Kué, J. Detection of several enzymatic activities in leaf prints of cucumber plant. Physiological and Molecular Plant Pathology, London, v.42, p.441-452, 1993.

3.Baraka, M. A.; Ghonim, M. I.; Abdel-Nabi, H. M.; Ahmed, M. I. Biochemical mechanisms of resistance in some bean cultivars against charcoal rot disease. Bulletin of Faculty of Agriculture, Cairo University, v.55, n.1, p.97 -- 120, 2004. In: CAB Abstracts. Disponível em:< http://periódicos.capes.gov.br >. Acesso em: 15 set. 2005.

4.Benizri, E.; Baudoin, E. ; Guckert, A. Root colonization by inoculated plant growth-promoting rhizobacteria. Biocontrol Science and Technology, Oxford, v.11, n.5, p.557-574, 2001.

5. Campos, A.D.; Ferreira, A.G.; Hampe, M.M.V.; Antunes, I.F.; Brancão, N.; Silveira, E.P.; Osório, V.A; Augustin, E. Atividade de peroxidase e polifenol oxidase na resistência do feijão à antracnose. Pesquisa Agropecuária Brasileira, Brasília, v.39, n.7, p. $637-643,2004$.

6.Hammerschmidt, R.; Nuckles, E.; Kuc, J. Association of enhanced peroxidase activity with induced systemic resistance of cucumber to Colletotrichum lagenarium. Physiology Plant Pathology, London, v.20, p.73-80, 1982.

7.Kado, C. I.; Heskett, M. G. Selective media for isolation of Agrobacterium, Corynebacterium, Erwinia, Pseudomonas and Xanthomonas. Phytopathology, St. Paul, v.60, p.24-30, 1970.

8.Laranzini, A. C.; Schons, J.; Wojahn, D.; Souza, R. Atividade de peroxidase e teores de proteínas induzidas por diferentes doses de ácido salicílico (AS) e ácido acetil salicílico (ASS) em plantas de tomate para controle do To $M V$. Fitopatologia Brasileira, Brasília, v.28, supl., p.371, 2003. (Resumo).

9. Mariano, R. L. R.; Romeiro, R. S. Indução de resistência sistêmica mediada por rizobactérias promotoras de crescimento d plantas. In: Melo, I. S.; Azevedo, J. L. Controle Biológico. Jaguariúna: Embrapa Meio Ambiente, 2000. v.2, p.305-324.

10. Mozzetti, C.; Ferraris, L.; Tamietti, G.; Matta, A. Variation in enzyme activities in leaves and cell suspension as markers of incompatibility in different Phytophthora-pepper interactions. Physiological and Molecular Plant Pathology, London, v. 46, n.2, p.95-107, 1995.

11. Ponting, J. D.; Joslyn, M. A. Aacorbic acid oxidation and browning in apple tissue extracts. Archives of Biochememistry, New York, v. 19, 47-63p., 1948.

12. Quan, L.F.; Sheng, W.J. Systemic induction of several defence response enzymes in rice seedlings by salicilic acid. Plant Physiology communications, v.38, n.2, p 123, 2002. In: CAB Abstracts. Disponível em: <http://periódicos.capes.gov.br>. Acesso em: 15 set. 2005 .

13. Ramamoorthy, V.; Raguchander, T.; Samiyappan, R. Induction of defense proteins in tomato roots treated with Pseudomonas fluorescens Pf1 and Fusarium oxysporum f. sp. lycopersici. Plant \& Soil, The Hague, v.239, n.1, p.55 - 68, 2002.

14. Rava, C.A. Patogenicidade de isolamentos de Xanthomonas campestris pv. phaseoli. Pesquisa Agropecuária Brasileira, Brasília, v. 19, p. 445-448, 1984. 
15. ROL, S. Protein purification techniques. 2. ed. Oxford: Oxford University Press, 2001. 262p.

16. Romeiro, R. S. PGPR e indução de resistência sistêmica em plantas a patógenos. Summa Phytopathologica, Botucatu, v.26, n.1, p.177-184, 2000.

17. Silva, E.G.; Moura, A.B.; Deuner, C.C.; Santos, A.S.; Farias, D.R.; Zanatta, Z.G.C.N. Incidência e severidade de crestamento bacteriano comum em feijoeiro originado de sementes microbiolizadas com bactérias selecionadas para biocontrole. In: Reunião De Controle Biológico De Fitopatógenos, 8, Ilhéus, 2003. Anais.... Ilhéus: CEPLAC, 2003.p. $99-100$.

18. Silva, H. S. A. ; Romeiro, R. S. ; Macagnan, D. ; Halfeld-Vieira, B. A. ; Baracat-Pereira, M. C. ; Mounteer, A. Rhizobacterial induction of systemic resistance in tomato plants: non-specific protection and increase in enzyme activities. Biological Control, Orlando, v. 29, n. 2, p. 288-295, 2004.

19. Soares, R.M.; Maringoni, A.C.; Lima, G.P.P.; Inefficiency of acibenzolar-S-methyl in induction of resistance against bacterial wilt in common bean. Fitopatologia Brasileira, Brasília, v.29, n.4, p.373-377, 2004

20. Southerton, S. G.; Deverall, B. J. Changes in phenylalanine ammonia-lyase and peroxidase activities in wheat cultivars expres- sing resistance to the leaf-rust fungus. Plant Pathology, St. Paul, v.39, p.223-230, 1990.

21. Srivastava, S. K. Peroxidase and poly-phenol oxidase in Brassica juncea plants infected with Macrophomina phaseolina (Tassai) Goid. and their implication in disease resistance. Journal of Phytopathology, Berlin, v.120, p.249-254, 1987.

22. Sticher, L.; Mauch-Mani, B.; Métraux, J. P. Systemic acquired resistance. Annual Review of Phytopathology, Palo Alto, v.35, p.235-270, 1997 .

23. Tuzun, S.; Kloepper, J.W. Potential application of plant growthpromoting rhizobacteria to induce systemic disease resistance. In: R. Hammerschmidt,; J. Kuc (Ed.), Induced resistance to diseases in plants. Dordrech: Kluwer Academic Publishers, 1995. p.115-127.

24. Van Loon, L. C.; Bakker, P. H. H. M.; Pieterse, C. M. J. Systemic resistance induced by rhizosphere bacteria. Annual Review of Phytopathology, Palo Alto, v.36, p.453-483, 1998.

25. Zanatta, Z.G.C.N.; Moura, A.B.; Maia, L.C.; Santos, A.S. Bioassay for selection of biocontroller bacteria against bean commnon blight (Xanthomonas axonopodis pv. phaseoli). Brazilian Journal of Microbiology, São Paulo, v.38, p. 511-515, 2007. 